\title{
Effect of Castor Oil Biodiesel Blending Ratio on Diesel Engine Performance and Emissions
}

\author{
Yousif Hassan Najim ${ }^{1}$, Ahmed Hasan Ahmed ${ }^{2}$, Waleed M.Sh. Al-Abdraba ${ }^{3}$ \\ \{engyousif123@gmail.com¹, ahmedaljibouri75@gmail.com², walabdraba@gmail.com ${ }^{3}$ \} \\ Environmental Engineering / Mosul University ${ }^{1}$, Technical Institute, Hawija/ Northern Technical \\ University ${ }^{2}$, Environmental Engineering / Tikrit University
}

\begin{abstract}
This study represents studying the production of biodiesel from castor oil and the effect of biodiesel/diesel mixing ratio on diesel engine performance and emissions. The in-situ method used to produce biodiesel from castor oil, Transesterification reaction was studied at a different molar ratio of methanol: oil from 6:1, 1:6.5, 1:7, 1:9, 1:12 to 15:1, at $65{ }^{\circ} \mathrm{C}$, reaction time up to 120 minutes and the mass ratio of catalyst to oil equal $1 \%$. All properties of biodiesel were identical to the ASTM standard. As for the process of separating glycerol from biodiesel. The results showed that the use of a mixer reduced the separation time to 2 hours. Fuel blends with $5 \%$ to $20 \%$ of castor oil biodiesel in diesel oil were tested, varying engine load from $20 \%$ to $80 \%$ of engine power. the exhaust concentrations was evaluated and The results showed, (CO) emissions was decreased by nearly $3.34 \%$ to $13.79 \%$, biodiesel decreased $(\mathrm{HC})$ emissions by $5.32 \%$ to $21.3 \%$, $(\mathrm{HCl})$ emissions decreased by $10.04 \%$ to $40.21 \%,\left(\mathrm{O}_{3}\right)$ emissions decreased by $34.72 \%$ to $82.87 \%,(\mathrm{Cl})$ emissions decreased by $4.75 \%$ to $30.12 \%$, (PM) emissions decreased by $8.5 \%$ to $34.76 \%$ and (NOx) emissions increased by $0.97 \%$ to $3.7 \%$ when diesel fuel blends containing $5 \%$ to $20 \%$ of biodiesel respectively in comparison with diesel fuel.
\end{abstract}

Keywords: Blended fuel, Diesel engine, Caster oil, Diethyl ether.

\section{Introduction}

In recent years, environmental concerns have been heightened; the depletion of petroleum resources and many other social and economic aspects have made it necessary to seek alternative fuels. Despite the problems in vegetable oils of high viscosity and engine injection problems, but these oils can become better when converting it to Esters, which has been called biodiesel [1]. Biodiesel is a clean alternative fuel, produced from renewable, biodegradable resources, non-toxic, sulfur-free and aromatic. Biodiesel is produced from a variety of sources, including animal fats and vegetable oils [2]. Basha et al. [3] reported that vegetable oil is an alternative fuel suitable for combustion engines in the form of (B 100) or mixed with fossil diesel. Lee et al. [4] describe the characteristics of atomic division and combustion characteristics of biodiesel in diesel engines. To study the properties of emissions of non-burning $\mathrm{HC}$, NOx, and $\mathrm{CO}$ were measured to detect the effect of mixing ratios for biodiesel. As the proportion of biodiesel to fossil fuels increases, $\mathrm{CO}, \mathrm{HC}$ emissions drop, and NOx emissions increase due to the oxygen in the biodiesel fuel.

Lin et al. [5] studied the impact of biodiesel produced from palm oil on engine performance, exhaust emissions, and combustion properties in a diesel engine with direct injection. The reduction in smoke was $37 \%$ and $60 \%$, NOx $1.5 \%$, and $2.5 \%$ when the engine 
speed was 2400 RPM, using B20 and B50, respectively, compared to fossil fuels. Non-burnt aromatic hydrocarbons (THC) decreased by 15 percent and 22 percent when the engine speed was 1200 cycles per minute using B20 and B50, respectively, compared to fossil diesel, the report said. Karra et al. [6] examined the characteristics of engine emissions using biodiesel mixed in systems with low combustion temperatures. The study indicates that the proportion of carbon (Soot), non-burnt hydrocarbon hydrocarbons (HC), and carbon monoxide decreased with B100, increasing NOx emissions and the proportion of biodiesel was increased when mixed with fossil diesel. Shahoo et al. [7] assessed the emissions and performance characteristics of biodiesel produced from jatropha, Karanga, and Polana in a tractor, using biodiesel ratios mixed with fossil fuels. The emissions for smoke, NOx, carbon oxides $\mathrm{CO}$, $\mathrm{CO} 2$, hydrocarbons $\mathrm{HC}$, and suspended PM were changed. For all ratios of biofuels mixed with fossil diesel, there is a significant reduction in smoke emissions.

Tzirakis et al. [8] examined the effect of mixing biodiesel with fossil diesel on composite emissions in real-life conditions. They noted that there was little difference in smoke opacity using B5 and B20 biodiesel compared with fossil diesel but observed when using B50, the transparency of smoke (smoke opacity) decreased by $27 \%$ compared to fossil diesel. Yoshida et al. [9] examined the effect of B30 biodiesel from rapeseed oil exhaust and exhaust emissions in the diesel engine, in which the researchers used a 4-cylinder Common Rail and Piezo Injector with a capacity of 2.2 liters, the reduction in PM emissions was 16\% compared to fossil diesel when B30 was used for rapeseed oil [10]. Others suggest that the reduction in PM is due to the presence or absence of aromatic compounds and sulfates in biodiesel[11]. A study had been done to test castor biodiesel fuel 5\% after mixed it with KKaranja biodiesel $10 \%$ with $85 \%$ hydrocarbon diesel fuel in a single-cylinder compersion ignition engine. The study showed that the mixture fuel is better than using diesel alone [12]. The current research aims to produce biodiesel from castor oil and test in a diesel engine. The fuel produced will be mixed with diesel in different proportions to study its effect on brake power and pollutants.

\section{Materials and Methods}

\subsection{Biodiesel production}

Castor oil was used because of uneatable oils, and in this respect, the global diet as most of the biofuel was made from eatable oils. The oil content is higher than 55\%, easy solubility in organic solvents even at normal temperatures, does not require much energy to produce as in the rest of the vegetable oils and because the ricinoleic acid is $90 \%$ of the composition of this oil. Therefore, this acid is responsible for improving the number of the system, which in turn improves the quality of combustion. This oil has been obtained from the local market as it is available in containers with a capacity of $1000 \mathrm{ml}$ of density equal to $967.3 \mathrm{~kg} / \mathrm{m}^{3}$ and its molecular weight $857 \mathrm{~g} / \mathrm{mol}$. Methanol is found in the local markets with purity $99.9 \%$ and molecular weight equal to $32.04 \mathrm{~g} / \mathrm{mol}$ and with a density of $972 \mathrm{~kg} / \mathrm{m}^{3}$. Base catalysts, such as $\mathrm{NaOH}$ and $\mathrm{KOH}$, act as catalysts for reactions.

The transesterification of production, initially the range for the operating condition was taken according to physical properties and stoichiometric ratio. Methanol has a boiling point of $64.7^{\circ} \mathrm{C}$. Therefore a higher level for reaction temperature was taken $65^{\circ} \mathrm{C}$ using condense. The esterification castor oil using a different Molar ratio of alcohol to oil to find the optimal ratio, which gives the highest conversion of oil to methyl ester, and these ratios were 1:6, 1:7, 1:9, $1: 12$ and 1:15. The reaction time is constant at $120 \mathrm{~min}$. The process was repeated under 
different reaction conditions. The optimum reaction conditions that resulted in maximum biodiesel yield of $98 \%$ are as follows: methanol to oil molar ratio of $1: 7, \mathrm{KOH}$ concentration of $1(\% \mathrm{w} / \mathrm{v})$, reaction time $120 \mathrm{~min}$, the reaction temperature of $65^{\circ} \mathrm{C}$ at a constant stirring rate of $700 \mathrm{rpm}$.

\subsection{Experimental Engine setup}

The engine tests of the fuel samples were performed on a Lombardini 5LD825-2/L tow-cylinder diesel engine with an air cooling system. Figure 1 shows a schematic diagram of the experimental engine setup, and the engine specifications are given in Table 1. The engine was coupled with an eddy current dynamometer with a capacity of $24 \mathrm{~kW}$, and a data logger was used, which controls and measures the effective torque, engine speed, and power. The tests were conducted at 20\%,40\%,60\%,80\% break power, and $1600 \mathrm{rpm}$, where the engine achieves the maximum torque.

Table 1. Engine specifications.

\begin{tabular}{cc}
\hline \hline Description & Specification \\
\hline Number of cylinders & Two in-line \\
Compression ratio & $17.5: 1$ \\
Total displacement $\left(\mathrm{cm}^{3}\right)$ & 1648 \\
Bore_stroke $(\mathrm{mm})$ & $100 \_105$ \\
Bore/stroke ratio & 0.952 \\
Combustion chamber & Swirl chamber \\
Fuel consumption & $190 \mathrm{gm} / \mathrm{HP} / \mathrm{hr}$ \\
Maximum power & $20 \mathrm{~kW} \mathrm{@} \mathrm{2600} \mathrm{rpm}$ \\
Maximum torque & $10.00 \mathrm{~kg} \mathrm{~m} @ 1700 \mathrm{rpm}$ \\
Inlet valve opening/closing $/{ }^{\circ} \mathrm{CA}$ & $12 \mathrm{BTDC} / 44 \mathrm{ABDC}$ \\
Exhaust valve opening/closing $/{ }^{\circ} \mathrm{CA}$ & 52 BBDC/12ATDC \\
\hline \hline
\end{tabular}

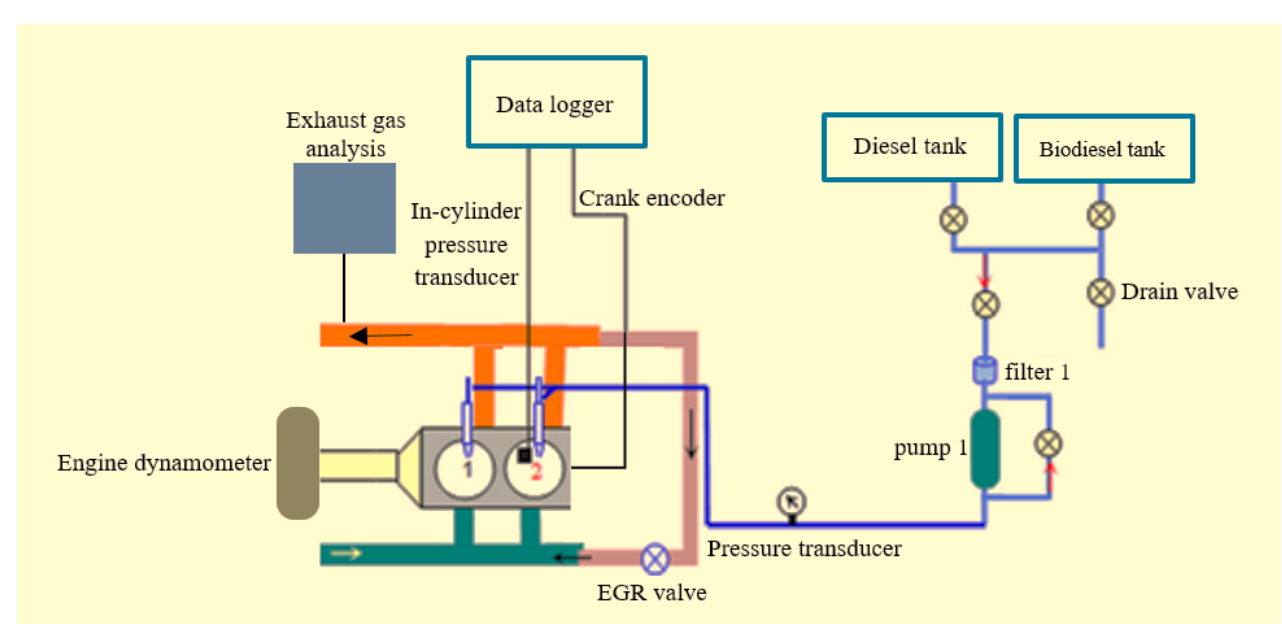

Fig. 1. Schematic diagram of the experimental engine test

\subsection{Emission tests}


This phase involves the test of biodiesel in a diesel engine and the analysis of emissions from the engine exhaust by gas analyzers. The WOLFPACK-GRAYWOLF was used to measure carbon monoxide $(\mathrm{CO})$, hydrocarbons $\mathrm{HC}, \mathrm{NOx}, \mathrm{HCl}, \mathrm{Cl}$, and $\mathrm{O}$ 3. SAS for PM. Samples of fossil diesel fuel mixed with certain percentages of biodiesel were used and compared with pollutants using fossil diesel alone in the engine.

An internal diesel engine with two cylinders connected to an external generator of 5000 watts is equipped with biodiesel, B5, B10, B15, and B20. The emissions of the engine equipped with these ratios of biodiesel were compared to emissions from the engine exhaust after processing with B0 fuel.

\section{Results and discussion}

\subsection{Fuel properties}

The physical properties of biodiesel produced from castor oil are tabulated in Table 2.

Table 2. The properties of produced biodiesel compared with ASTM.

\begin{tabular}{llll}
\hline \hline \multicolumn{1}{c}{ Physical properties } & \multicolumn{1}{c}{ B100 } & Property according to ASTM & Property limit \\
\hline Specific gravity at $15.6^{\circ} \mathrm{C}$ & 0.87 & ASTM D-941 & $0.860-0.900$ \\
API value & 31.14 & ASTM D-941 & $0-100$ \\
Kinematic viscosity at $\mathrm{mm}^{2} / \mathrm{s}$ at & 11.8 & ASTM D-445 (IP71) & $1.9-6$ \\
$40^{\circ} \mathrm{C}$ & 194 & ASTM D93 & 130 min \\
Flash point ${ }^{\circ} \mathrm{C}$ & 50.19 & ASTM D-6890 & $40.5-55.3$ \\
Cetin number & -24 & ASTM D-97 & Unlimited \\
Pour point & 0.5 & ASTM D-2709 & $3.5 \%-5.0 \%$ \\
Water content $\%$ & 0.0008 & ASTM D-524 IP14/65 & 0.05 max \\
Residual carbon & 0.02 & ASTM D-6751-10 & 0.02 max \\
Ash content $\mathrm{mg} / \mathrm{kg}$ & 334 & ASTM D-6751-10 & 360 max \\
Distillation ${ }^{\circ} \mathrm{C} 90 \%$ & & &
\end{tabular}

\subsection{Diesel engine emissions}

\subsubsection{The impact of biodiesel on carbon monoxide emissions}

In Figure 2, carbon monoxide (CO) emission concentrations are observed by changing loads from 0 to $80 \%$ and by changing the percentages of biodiesel fuel using B0 to B20. 


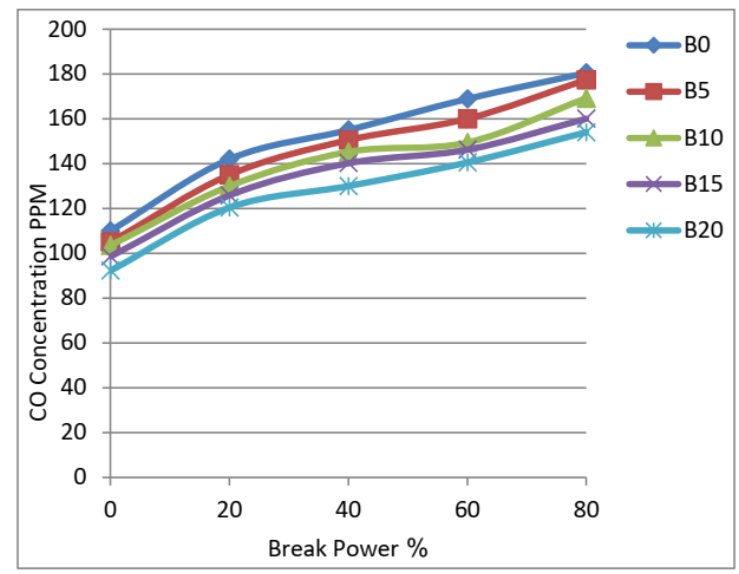

Fig. 2. Variation in CO ppm emissions with varying biodiesel blending and load conditions

The results obtained can be summed up with the results in Table 3, showing the effect of biodiesel blending rates on the reductions in the concentrations of carbon monoxide.

Table 3. Effect of biodiesel blending rates on the reductions in the concentrations of CO.

\begin{tabular}{lc}
\hline \hline $\begin{array}{l}\text { Reduction in carbon monoxide emissions for } \mathrm{B}_{0} \\
\text { emissions }(\%)\end{array}$ & Biodiesel blends \\
\hline 3.34 & $\mathrm{~B} 5$ \\
6.56 & $\mathrm{~B} 10$ \\
9.62 & $\mathrm{~B} 15$ \\
13.79 & $\mathrm{~B} 20$ \\
\hline \hline
\end{tabular}

The use of biodiesel blending with fossil fuels has reduced the concentrations of carbon monoxide $(\mathrm{CO})$ emissions. The reduction rates have increased with the increase in mixing ratios and the reduction in emissions due to the biodiesel properties produced from castor oil. The results of previous research indicate that the secret in reducing carbon monoxide (CO) emissions is related to the properties of raw materials, including biodiesel. Biodiesel contains a high concentration of oxygen in its composition, as well as ricinoleic acid, which is a major component of castor oil, which is related to improving the quality of combustion, making fuel combustion almost complete. The high concentration of oxygen and the chemical composition of castor oil cause a reduction in concentrations of carbon monoxide $(\mathrm{CO})$ of other types of biodiesel.

\subsubsection{Effect of biodiesel on hydrocarbon emissions}

In Figure 3, the concentrations of HC hydrocarbon emissions vary by changes in loads 0 to $80 \%$ and changes in biodiesel. 


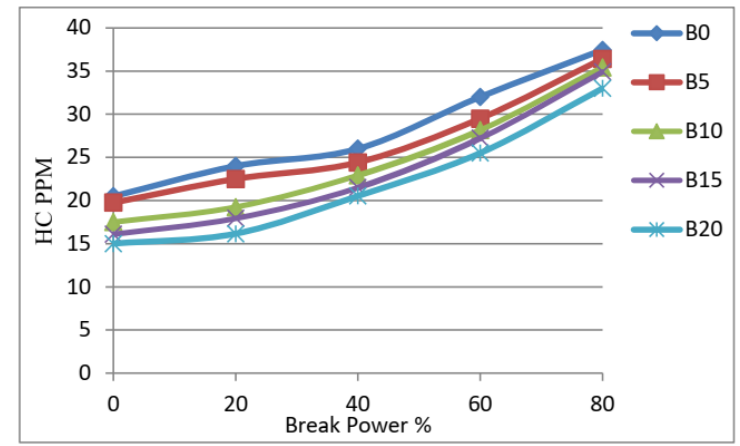

Fig. 3. Variation in $\mathrm{HC}$ with break power for biodiesel blending

The results obtained can be summed up with the results in Table 4, showing the effect of biodiesel blending rates on the reductions in the concentrations of unburned hydrocarbons.

Table 4. Effect of biodiesel blending rates on the reductions in the concentrations of unburned HC.

Reduction in the concentration of hydrocarbons

For B0 emissions (\%)

Biodiesel Blends

$\begin{array}{lc}5.32 & \text { B5 } \\ 11.97 & \text { B10 } \\ 15.95 & \text { B15 } \\ 21.3 & \text { B20 }\end{array}$

The reason for the reduction in concentrations of $\mathrm{HC}$ using biodiesel is the high oxygen content compared to fossil diesel. The high concentration of oxygen in the bio-fuel structure, which makes up about $11 \%$ of its weight, results in complete combustion reduces non-burning fuel (hydrocarbons). Unburned hydrocarbons are unburned fuels that are formed by a combustion defect results in the release of some unburned or semi-burnt fuel, thereby reducing the proportion of non-burnt hydrocarbon hydrocarbons. The results of previous research were consistent with what was obtained during the examinations $[9,13]$.

\subsubsection{The impact of biodiesel on hydrogen chloride emissions}

Figure 4 shows the change in the concentration of $\mathrm{HCl}$ emissions with load changes from 0 to $80 \%$ and changes in biodiesel from B0 to B20.

The results obtained can be summed up with the results in Table 5, showing the effect of biodiesel mixing rates on the reduction rates in the concentrations of hydrogen chloride gas.

Table 5. Effect of biodiesel mixing rates on reduction concentrations of $\mathrm{HCl}$.

\begin{tabular}{cc}
\hline \hline Reduction in emissions of hydrogen chloride gas for & Biodiesel \\
B0 emissions $(\%)$ & B5 \\
\hline 10.04 & B10 \\
23.09 & B15 \\
30.8 & B20 \\
40.21 & \\
\hline
\end{tabular}




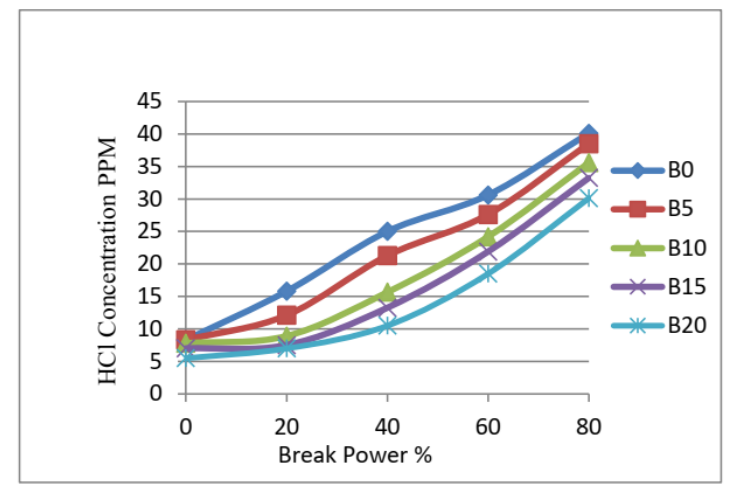

Fig. 4. Variation of the $\mathrm{HCl}$ with break power for biodiesel blending.

Hydrogen chloride gas is formed as a result of the direct interaction between hydrogen $\mathrm{H}_{2}$ and $\mathrm{Cl}_{2}$, as in Eq. (1).

$$
\mathrm{Cl}_{2}+\mathrm{H}_{2} \rightarrow 2 \mathrm{HCl}
$$

Hydrogen chloride is formed from the chlorination of aromatic hydrocarbons as a secondary product, as in Eq. (2).

$$
\mathrm{C}_{6} \mathrm{H}_{6}+\mathrm{Cl}_{2} \rightarrow \mathrm{C}_{6} \mathrm{H}_{5} \mathrm{Cl}+\mathrm{HCl}
$$

The chlorine is part of the composition of fossil diesel, and ASTM specifies the standard ASTM D5384-14 to measure the ratio of chlorine in the composition of fossil diesel. The main reason for the reduction of chlorine gas concentrations is the lack of chlorine in the installation of biodiesel. The aromatic compounds are not involved in the installation of fuel Biodiesel; therefore, chlorine gas concentrations are less than those of bio-fuel engines.

\subsubsection{The impact of biodiesel on chlorine emissions}

Figure 5 shows the change in concentrations of chlorine emissions, changing the loads ( 0 to $80 \%$ ), and changing biodiesel.

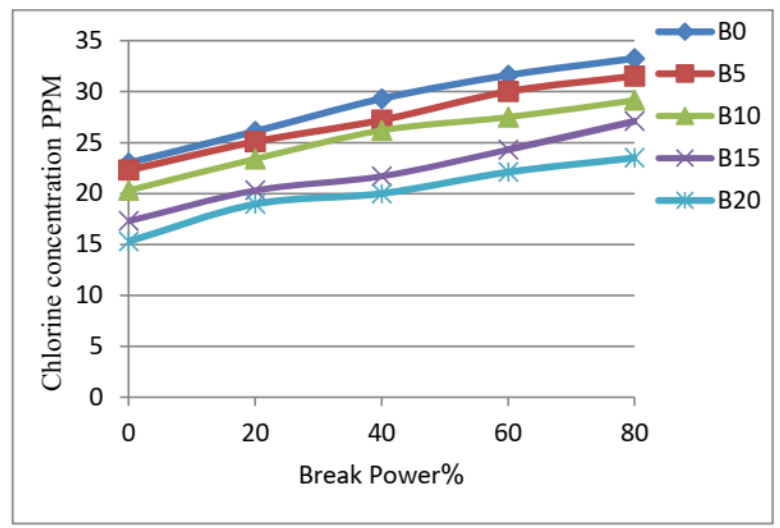

Fig. 5. Variation in chlorine with varying biodiesel blending and load conditions 
The result of Figure 5 can be summarized in the results in Table 6, as it shows the effect of biodiesel mixing rates on the reduction rates in chlorine emissions.

Table 6. Effect of biodiesel mixing rates on the reduction of $\mathrm{Cl}$ emissions.

\begin{tabular}{cc}
\hline \hline Reduction in chlorine emissions (\%) & Biodiesel Blends \\
\hline 4.75 & B5 \\
11.48 & B10 \\
22.53 & B15 \\
30.12 & B20 \\
\hline \hline
\end{tabular}

The inclusion of fossil diesel in chlorine in its composition is one of the reasons for its emissions from the exhaust of internal combustion engines supplied with fossil diesel. When using the combination of fossil diesel and biodiesel, the concentration of chlorine gas has decreased with the concentration of biofuels in fossil fuels and the lack of chlorine biodiesel in its composition is the main reasons for the reduction of concentrations of emissions from the internal combustion engine with a mixture of B5 - B20. However, concentrations of chlorine emissions were not high, it did not exceed $35 \mathrm{ppm}$, so it is dangerous when compared with the large sources.

\subsubsection{The impact of biodiesel on ozone emissions}

Figure 6 shows the change in $\mathrm{O}_{3}$ emission concentrations with load changes from 0 to $80 \%$ and changes in the biodiesel ratio.

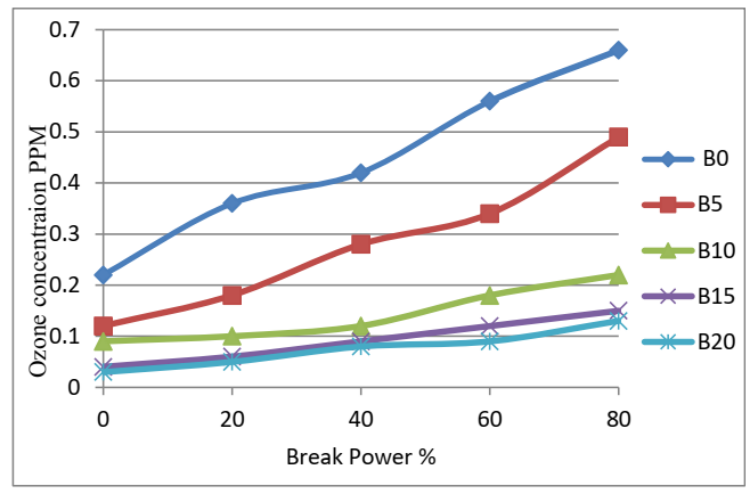

Fig. 6. Variation in Ozone with varying biodiesel blending and load conditions

The results in Table 7 can summarize the result of Figure 6, as it shows the effect of biodiesel mixing rates on the reduction rates in $\mathrm{O}_{3}$ emission concentrations.

Table 7. Effect of biodiesel mixing rates on the reduction of $\mathrm{O}_{3}$ emission.

\begin{tabular}{cc}
\hline \hline $\begin{array}{c}\text { Reduction in ozone gas emissions } \\
\text { For B0 emissions }(\%)\end{array}$ & Biodiesel blends \\
\hline 34.72 & B5 \\
65.27 & B10 \\
78.70 & B15 \\
82.87 & B20 \\
\hline \hline
\end{tabular}


Ozone gas is composed of internal combustion engines, the most important source of which is the exposure of the oxygen molecule to electric discharge in the combustion chamber, which leads to two atoms that can interact with another oxygen molecule to form ozone $\mathrm{O}_{3}$ according to Eq. (3).

$$
\mathrm{O}+\mathrm{O}_{2} \rightarrow \mathrm{O}_{3}
$$

Ozone is formed by the reaction of NOx and volatile organic compounds (VOCs) as Eq. (4).

$$
\mathrm{NOX}+\mathrm{VOCs}+\text { sunlight } \rightarrow \mathrm{O}_{3}
$$

It can also be composed of the reaction of $\mathrm{NO}_{2}$ and $\mathrm{O}_{2}$ as in Eq. (5).

$$
\mathrm{NO}_{2}+\mathrm{O}_{2} \rightarrow \mathrm{NO}+\mathrm{O}_{3}
$$

The use of biodiesel has led to a significant reduction of $\mathrm{O}_{3}$ emissions to $83 \%$. The reason for the reduction of $\mathrm{O}_{3}$ concentrations is the interaction between $\mathrm{NOx}$ and $\mathrm{O}_{3}$, which is the biggest reason for the reduction of NOx concentrations in the abundance of NOx in the mixture exhaust gases from internal combustion engines with biodiesel as in Eq. (6).

$$
\mathrm{NO}+\mathrm{O}_{3} \rightarrow \mathrm{NO}_{2}+\mathrm{O}_{3} \quad \text { (6) }
$$

Although the $\mathrm{O}_{3}$ emissions concentrations were as little as $0.5 \mathrm{ppm}$, they could cause a clear imbalance in nature because the source of these pollutants is much more than the biodiesel, an ideal solution to reduce $\mathrm{O}_{3}$ emissions.

\subsubsection{The impact of biodiesel on the emissions of particulate matter and NOx}

Figure 7 shows the change in PM concentrations by changing loads from 0 to $80 \%$ and by changing the rates of biodiesel fuel.

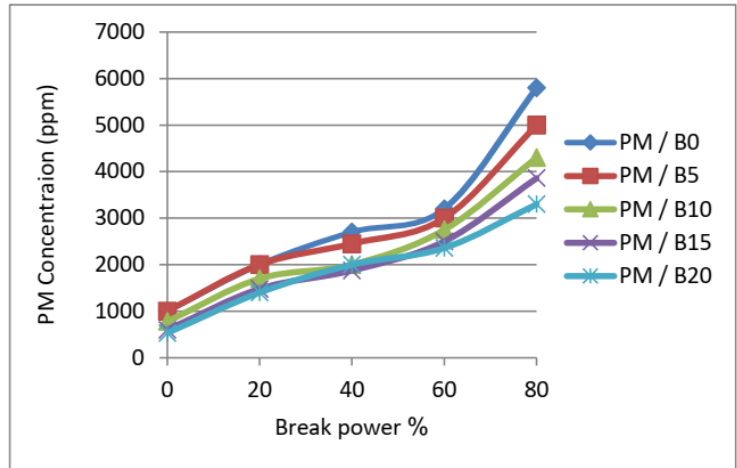

Fig. 7. Variation in PM with varying biodiesel blending and load conditions

The results in Table 8 can summarize the results of Figure 7 as it shows the effect of biodiesel mixing rates on the reduction rates in the PM concentrations.

Table 8. Effect of biodiesel mixing rates on the reduction rates in the PM.

\begin{tabular}{cc}
\hline \hline $\begin{array}{c}\text { Reduction in emissions of particulate matter } \\
\text { For B0 emissions }(\%)\end{array}$ & $\begin{array}{c}\text { Biodiesel } \\
\text { Blends }\end{array}$ \\
\hline 8.5 & B5 \\
21.56 & B10 \\
30.32 & B15 \\
34.76 & B20 \\
\hline \hline
\end{tabular}




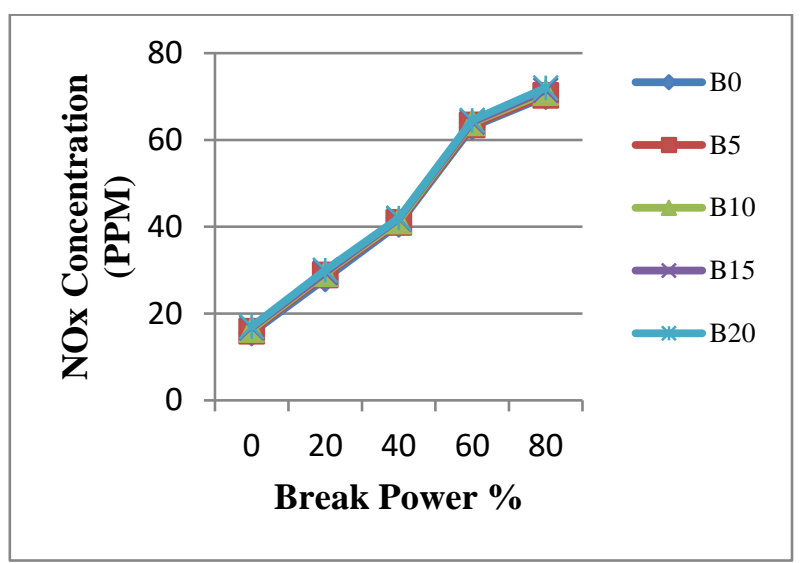

Fig. 8. Variation in NOx with varying biodiesel blending and load conditions

The results shown in Figure 8 show a slight increase in NOx emissions when biodiesel is mixed with fossil diesel. The reason for this increase is due to several interpretations since most researchers believe that the high concentration of oxygen and the high density of biofuels are the main reason for increasing NOx concentrations. The other reason is that the increase in NOx concentrations is due to combustion processes due to different chemical properties of fuel $[14,15,17]$.

The association of NOx concentration with biofuels has led researchers to undertake extensive studies to understand the NOx mechanism and increase its concentrations in the presence of biodiesel. The high value of kinematic and density kinetics changes the fuel injection mechanism and affects combustion compared with fossil fuels. During the change in the amount of fuel injected over a period of time, as well as the effect of injection timing and fuel injection pattern injected into the combustion chamber, the Common Rail Injection System relies on the direct viscosity of the fuel $[11,16,19]$.

The thermal value of biofuels is about $12 \%$ less than the thermal value of fossil fuels, which leads to the loss of part of the engine capacity, which must be compensated to balance the loss of energy by increasing the amount of fuel injected and the early start of fuel injection over a period of time and this makes the injection needle open more for a period Which causes the combustion temperature to rise and increase the pressure which leads to NOx. This is one of the reasons. The other reason is the properties of the al physic-chemical fuels such as the oxygen content and the acid content $(\mathrm{C}-18-\mathrm{OH})$, which improves the quality of combustion by reducing the delay time of the mug (Ignition Delay). This leads to high combustion temperature, pressure, and high oxygen content improves combustion flame (NO) [11,16] and has led to higher temperatures in the combustion chamber. This is consistent with researchers $[9,14]$.

\section{Conclusion}

1. Reduction of carbon monoxide (CO) emissions by using biodiesel produced from castor oil at rates ranging from $3.34 \%$ to $13.79 \%$ when using B5 to B20, respectively, compared to fossil diesel. 
2. We are reducing the concentrations of hydrocarbon emissions $\mathrm{HC}$ using biodiesel produced from castor oil at rates ranging from $5.32 \%$ to $21.3 \%$ when using B5 to B20, respectively, compared to fossil diesel.

3. Reduce PM concentrations by using biodiesel produced from castor oil at rates ranging from $8.5 \%$ to $34.76 \%$ when using B5 to B20, respectively, compared to fossil diesel.

4. Reduction of $\mathrm{HCl}$ emissions using biodiesel produced from castor oil at rates ranging from $10.04 \%$ to $40.21 \%$ when using B5 to B20, respectively, compared to fossil diesel.

5. They are reducing $\mathrm{O}_{3}$ emissions by using biodiesel produced from castor oil at rates ranging from $34.72 \%$ to $82.87 \%$ when using B5 to B20, respectively, compared to fossil d, which is the largest reduction achieved in the research.

6. Reducing concentrations of chlorine emissions by using biodiesel produced from castor oil at rates ranging from $4.75 \%$ to $30.12 \%$ when using B5 to B20, respectively, compared to fossil diesel.

7. Increased concentrations of NOx emissions using biodiesel produced from castor oil at percentages ranging from $0.97 \%$ to $3.7 \%$ when using B5 to B20, respectively, compared to fossil diesel.

\section{References}

[1] A.K. Agarwal, Biofuels (Alcohols and Biodiesel) Applications as Fuels for Internal Combustion Engines, Progress in Energy Combust Science, Vol. 33, pp. 233-271, 2007.

[2] S. Tayal, Detection of Cold Flow Properties of Diesel and Biodiesel Fuel Using Optical Sensor, M.Sc. Thesis, University of Missouri-Columbia, 2006.

[3] S. A. Basha, G. K. Raja, S. Jebaraj, A review on biodiesel production, combustion, emission, and performance, Renew. Sustain. Energy Rev.vol.13, pp. 1628-1634, 2009.

[4] C. Lee, S. Park, S. Kwon, an experimental study on the atomization and combustion characteristics of biodiesel-blended fuels, Energy \& Fuels. Vol. 19, 2201-8, 2005.

[5] C. Y. Lin and C. C. Chiu, Effects of Oxidation during Long-term Storage on the Fuel Properties of Palm Oilbased Biodiesel, Energy \& Fuels, Vol. 23, PP. 3285-3289, 2009.

[6] P. K. Karra, M. K. Veltman, and S. C. Kong, Characteristics of Engine Emissions Using Biodiesel Blends in Low-Temperature Combustion Regimes, Energy \& Fuels, Vol.22, 2008.

[7] P.K. Sahoo, L.M. Dasa, M. K. G. Babu, P. Arora, V.P. Singh, N.R. Kumar, and T.S. Varyani, Comparative Evaluation of Performance and Emission Characteristics of Jatropha, Karanja and Polanga Based Biodiesel as Fuel in a Tractor Engine, Fuel Journal, Vol. 88, No. 9, PP. 1698-1707, 2009.

[8] E. Tzirakis, G. Karavalakis, F. Zannikos, and S. Stournas, Impact of Diesel/Biodiesel Blends on Emissions from a Diesel Vehicle Operated in Real Driving Conditions, SAE Paper, No. 01, pp. 0076, 2007.

[9] K. Yoshida, S. Taniguchi, K. Kitano, Y. Tsukasaki, R. Hasegawa, and I. Sakata, Effects of RME30 on Exhaust Emissions and Combustion in a Diesel Engine, SAE paper, No. 01, pp. 2499, 2008.

[10] G. Karavalakis, E. Bakeas, and S. Stournas, An Experimental Study on Impact of Biodiesel Origin and Type on the Exhaust Emissions from a Euro 4 Pick-up Truck, SAE Paper, Vol. 3, PP. 995-1011, 2010.

[11] M. Lapuerta, O. Armas and J. Rodriguez-Fernandez, Effect of Biodiesel Fuels on Diesel Emissions, Progress in Energy and Combustion Science, Vol. 34, PP. 198-223, 2008.

[12] K. Kahkashan, K. Gitesh, K. S. Amit, P. S. Kumar, M. Chandan \& V. Chintala, Performance and emission characteristics of a diesel engine using a complementary blending of castor and karanja biodiesel, Biofuels, ISSN: 1759-7269 (Print) 1759-7277 (Online)

[13] M. Sanjeev, K. Suhas, D. Winfried, and K. Stefan, On-Road Testing of AdvancedCommon Rail Diesel Vehicles with Biodiesel from the Jatropha Curcas plant, SAE Paper, No. 26, pp. 35, 2005.

[14] R. McGill, J. Storey, R. Wagner, D. Irick, P. Aakko, M. Westerholm, N. Olof-Nylund, and M. Lappi, Emission Performance of Selected Biodiesel Fuels, SAE Paper, No. 01, pp. 1866, 2003.

[15] F. Georgios, S. Zissis, and M. Georgios, Experimental Evaluation of Cottonseed Oil Diesel Blends as Automotive Fuels via Vehicle and Engine Measurements, SAE Paper, No. 24, pp. 0126, 2007.

[16] C. Chuk, From Cultivation to Combustion". A Scientific Review of Biodiesel, The University of Bath, 2007. 
[17] D. Vashist, M. Ahmad, Comparative Study of Performance and Emission Characteristics of a Diesel Engine Fueled by Castor and Jatropha Methyl Ester with the Help of T Test, International Journal of Automotive Engineering, Vol. 2, No. 2, 2012.

[18] S. J. Pankaj, K. Farman, S. Radhey, Experimental Investigation to Evaluate the Performance, Emission and Combustion Characteristics of Diesel Engine with Castor Oil Biodiesel, International Journal of Engineering Science Invention Research \& Development, Vol. II, Issue II, 2015.

[19] D. Mithun, S. Mouktik, D. Amitava, K. S. Apurba, An experimental study on the combustion, performance And emission characteristics of a diesel engine fuelled with diesel castor oil biodiesel blends, Renewable Energy, 2017, DOI:10.1016/j.renene. 2017.12.014, S0960-1481(17)31210-7. 